\title{
SPECTROSCOPIC STUDIES OF NEODYMIUM AND EUROPIUM PHOSPHORO-AZO $\beta$-DIKETONATES
}

\author{
V. Amirkilanov, V. Ovcinnnikov \\ Department of Chemistry, Kiev State University \\ Vladimirskaja 64, 252033 Kiev, Ukraine \\ J. LEGENDZIEWICZ
}

Faculty of Chemistry, Wrocław University, 14 F. Joliot-Curie, 50-383 Wrocław, Poland

A. GracZYK

Institute of Chemistry, Military Technical Academy

Kaliskiego 2, 01-489 Warsaw, Poland

J. HANUza AND L. MACALIK

Institute for Low Temperature and Structure Research

Polish Academy of Sciences, Okólna 2, 50-950 Wrocław, Poland

\begin{abstract}
New complexes of lanthanides (Nd, Eu) with phosphoro-azo derivatives of $\beta$-diketoncs were synthesized. Optical properties of these compounds were investigated and confronted with the structure and single crystal spectra of different types of earlier reported lanthanide phosphoro-azo $\beta$-diketonates. The exchange of the N-P-O-Me ligand group by the $\mathrm{N}-\mathrm{P}-\mathrm{NR}_{2}$ one plays only a minor role in binding character of lanthanide ions but strongly affects biological functions and properties of lanthanide systems. In vitro experiment on cytotoxicity of the samples was performed using $10 \mathrm{~T}_{1 / 2}, \mathrm{~L}_{1}, \mathrm{MCF}, \mathrm{DETA}$ and Me $\omega-132$ cell lines.
\end{abstract}

PACS numbers: 78.20.Wc, 78.55.Hx, 78.20.Dj

\section{Introduction}

Phosphoro-azo derivatives of $\beta$-diketone are applied in clinical practice as anticancer medicals $[1,2]$. The role and function of chelating part of $-\mathrm{CO}-\mathrm{NH}-\mathrm{PO}<$ ligand are not known in this process. To our knowledge, lanthanide phosphoro-azo $\beta$-diketonates have not been examined as antitumor agents yet. Recently we undertook studies on physicochemical propeities of two series of complexes with two kinds of $\beta$-diketones: $A$ with $\mathrm{CCL}_{3}-\mathrm{C}(\mathrm{O}) \mathrm{N}-\mathrm{P}(\mathrm{O})\left(\mathrm{OCH}_{3}\right)_{2}$ derivatives, which were reported in [3], and $B$ with $\mathrm{CCL}_{3}-\mathrm{C}(\mathrm{O}) \mathrm{N}-\mathrm{P}(\mathrm{O})\left[\mathrm{N}\left(\mathrm{CII}_{2}\right)_{2}\right]_{2}$. The aim of this paper was to explain the structure and cytotoxicity of the latter type of compound. 


\section{Experimental}

Lanthanides $\beta$-diketonates of $B$ type were synthesized according to the procedure described in [3].

Absorption spectra at $293 \mathrm{~K}$ were measured by a Cary Varian 5 spectrophotometer. Excitation and emission spectra were recorded at 77 and $293 \mathrm{~K}$ using a SLM Aminco 500 spectrofluorometer. IR spectra were obtained using a Brüker FS 88 FTIR spectrometer, while the Raman ones - with a DFS 24 double monochromator equipped with photon counting system. An argon ion laser was used as an excitation source.

\section{Results and discussion}

As it was mentioned above, the phosphoro-azo derivatives of $\beta$-diketone are applied in anticancer medicine. Ilowever, cytotoxicity of these compounds is relatively high. Studies of lanthanide complexes were undertaken to explain the role of metal ion in enlancenent or inhibition of the ligand properties. Moreover, the process of complexation could limit moiety of the $\mathrm{C}(\mathrm{O})-\mathrm{N}-\mathrm{P}(\mathrm{O})-\mathrm{N}$ part of the ligand molecule, explaining the role of this part in biological activity. The main goal of our investigations was the synthesis of samples of excellent quality. Next, their spectroscopic properties throw light on the problem of structure of these systems. Finally, the effort has been made to test the cytotoxicity behaviour of the samples using four different ccll lines (in vilro experiments).
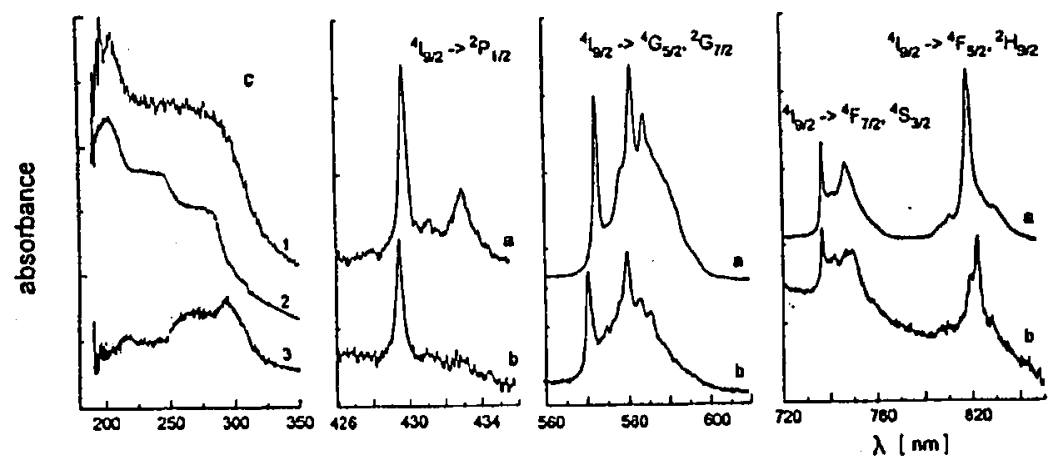

Fig. 1. The absorption spectra of $a-\mathrm{Na}\left[\mathrm{NdWO}_{4}\right] \cdot \mathrm{H}_{2} \mathrm{O}$ single crystal, and $\boldsymbol{b}$ $\mathrm{Na}\left[\mathrm{NdAz}_{4}\right] \cdot \mathrm{H}_{2} \mathrm{O}$ in the visible and UV region, $c$ - these of $\mathrm{Na}\left[\mathrm{EuAz}_{4}\right](1), \mathrm{HAz}(2)$, and $\mathrm{Na}[\mathrm{EuAz}]$ vs. $\mathrm{HAz}(3)$.

Figure 1 shows the absorption spectrum of neodymium powder complex with $B$, and a single crystal spectrum of neodymium complex with $A$ kinds of ligand in the range of NIR and hypersensitive transitions, which are the most sensitive to the changes of lanthanide ion environment. Both the splitting of bands and relative intensities of $f-f$ transitions (Table I) are comparable to those observed in the spectra of sample $A$, whose structure was well-defined by X-ray method. 
TABLE I

Oscillator strength values $\left(P_{\exp } \times 10^{8}\right)$ of $f-f$ transitions for simple crystal of $\mathrm{Na}\left[\mathrm{NdWO}_{4}\right] \cdot \mathrm{H}_{2} \mathrm{O}$ and for $\mathrm{Na}\left[\mathrm{NdAz}_{4}\right] \cdot \mathrm{H}_{2} \mathrm{O}$ in powder.

\begin{tabular}{c|c|c|c|c}
\hline \hline \multirow{2}{*}{$S^{\prime} L^{\prime} J^{\prime}$} & $\begin{array}{c}\text { pectral region } \\
{[\AA]}\end{array}$ & \multicolumn{2}{|c|}{$\mathrm{Na}\left[\mathrm{NdWO} \mathrm{N}_{4}\right] \cdot \mathrm{II}_{2} \mathrm{O}$} & $\begin{array}{c}\mathrm{Na}\left[\mathrm{NdAz}_{4}\right] \cdot \mathrm{H}_{2} \mathrm{O} \\
(C \cdot D=1)\end{array}$ \\
\cline { 3 - 5 } & & $293 \mathrm{~K}$ & $5 \mathrm{~K}$ & $293 \mathrm{~K}$ \\
\hline${ }^{4} F_{3 / 2}$ & $8400-9200$ & 422.3 & 210.8 & 44.05 \\
${ }^{4} F_{5 / 2},{ }^{2} H_{9 / 2}$ & $7750-8450$ & 949.2 & 651.1 & 85.40 \\
${ }^{4} F_{7 / 2},{ }^{4} S_{3 / 2}$ & $7100-7750$ & 873.1 & 523.3 & 87.32 \\
${ }^{4} F_{9 / 2}$ & $6610-7050$ & 61.5 & 51.1 & 9.42 \\
${ }^{4} G_{5 / 2},{ }^{2} G_{7 / 2}$ & $5500-6100$ & 1837.7 & 1458.2 & 287.31 \\
${ }^{2} K_{13 / 2},{ }^{4} G_{7 / 2},{ }^{4} G_{9 / 2}$ & $4900-5500$ & 788.0 & 542.2 & 118.85 \\
${ }^{2} K_{15 / 2},{ }^{2} G_{9 / 2}$, & $4500-4900$ & 216.4 & 205.8 & 28.25 \\
$\left.{ }^{2} D,{ }^{2} F\right)_{3 / 2},{ }^{4} G_{11 / 2}$ & & & & \\
${ }^{2} P_{1 / 2},{ }^{2} D_{5 / 2}$ & $4130-4400$ & 57.9 & 38.6 & 6.83 \\
${ }^{4} D_{3 / 2},{ }^{4} D_{5 / 2},{ }^{2} I_{11 / 2}$, & $3380-3700$ & 1206.2 & 899.4 & 65.19 \\
${ }^{4} D_{1 / 2},{ }^{2} L_{15 / 2}$ & & & & \\
${ }^{2} I_{13 / 2},{ }^{4} D_{7 / 2},{ }^{2} L_{17 / 2}$ & $3200-3380$ & 267.5 & 260.4 & -
\end{tabular}

Note that in $A$ the sodium ions are encapsulated inside the structure of the complexes [3]. In the system presented here situation could be changed because of steric factors.

UV region of absorption of complexes is dominated by a charge-transfer (C-T) band (Fig. 1c); this region is also that of transitions inside ligand. Rélative positions of bands are presented in Fig. $1 c-1,2,3$. Their role in the emission process will be the subject of our future studies.

Let us confront the excitation spectra obtained at 293 and $77 \mathrm{~K}$ (Fig. 2) and compare them with the data of complex $A$. At room temperature, the ${ }^{7} F_{0} \rightarrow{ }^{5} D_{2}$ transition is the strongest line in the spectrum; similarly, strong ${ }^{7} F_{1} \rightarrow{ }^{5} D_{1}$ band shows significant population of the ${ }^{7} F_{1}$ level.

When lowering temperature, a strong and broad UV band appears; moreover, relative intensities of ${ }^{7} F_{0} \rightarrow{ }^{5} L_{6},{ }^{5} D_{2}$ transitions change significantly. Splitting of the ${ }^{7} F_{0} \rightarrow{ }^{5} D_{J}$ transition is close to that in compound $A$, indicating similarity of structures. Moreover, the number of the Stark components in the emission spectra and shapes of bands remind those in the spectrum of single crystal of $A$ (Fig. 3).

The above data confirm well similarities of the two kinds of compounds. Inspection of IR and Raman results in the range of modes which are most sensitive to the bonding of metal ion yields further evidence for analogies in the bonding. The IR and Raman spectra indicate that the structure of the complexes studied is composed of octacoordinated $\mathrm{LnO}_{8}$ polyhedra. The stretching $\nu(\mathrm{Ln}-\mathrm{O})$ vibrations occur in the $170-360 \mathrm{~cm}^{-1}$ region and the bending modes appear below $150 \mathrm{~cm}^{-1}$. The bands corresponding to these vibrations are split into distinct doublets. Such 


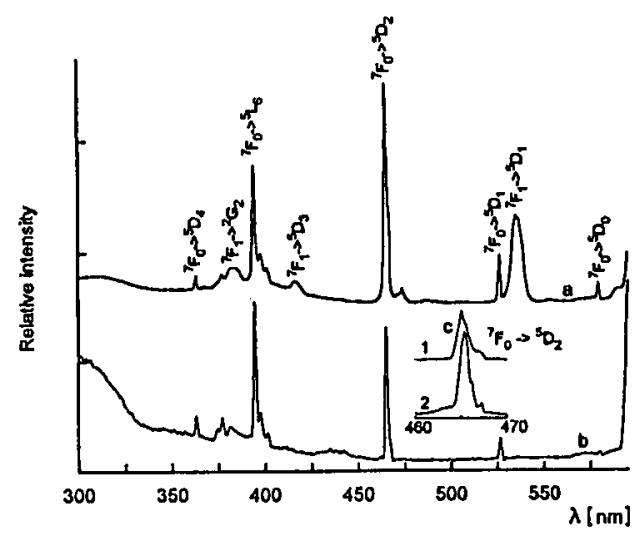

Fig. 2. The excitation spectra $\mathrm{Na}\left[\mathrm{EuAz}_{4}\right] \cdot \mathrm{II}_{2} \mathrm{O}$ at $293 \mathrm{~K}(a)$ and at $77 \mathrm{~K}(b)$, and comparative data for $\mathrm{Na}\left[\mathrm{EuAz}_{4}\right] \cdot \mathrm{II}_{2} \mathrm{O}(1)$ and $\mathrm{Na}\left[\mathrm{EuWo}_{4}\right] \cdot \mathrm{I}_{2} \mathrm{O}(2)$ at $77 \mathrm{~K}$ in the range of ${ }^{7} F_{0} \rightarrow{ }^{5} D_{2}$ transition (c).
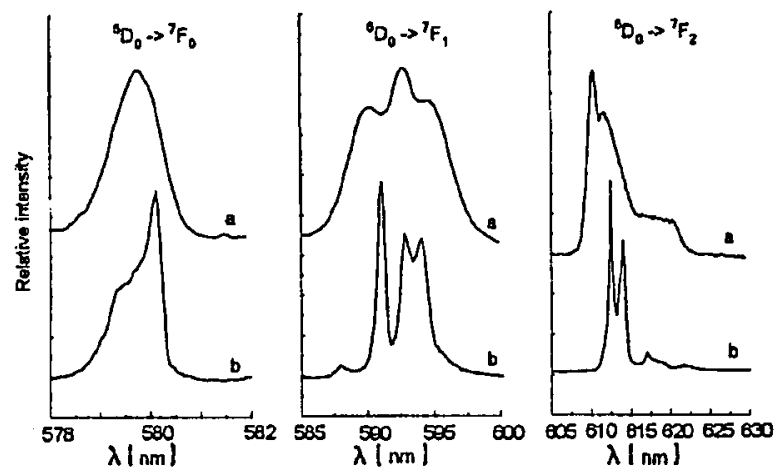

Fig. 3. Comparative results for $\mathrm{Na}\left[\mathrm{EuAz}_{4}\right] \cdot \mathrm{H}_{2} \mathrm{O}(a)$ and $\mathrm{Na}\left[\mathrm{EuWo}_{4}\right] \cdot \mathrm{H}_{2} \mathrm{O}(b)$ in emission spectra at $77 \mathrm{~K}$.

behaviour is characteristic of the case when the $\mathrm{LnO}_{8}$ polyhedron contains two sets of the Ln-O distances with significantly different values. It means that the structure of the polyhedron, which occupies the general positions, could be described by the Archimedean antiprismatic symmetry.

Almost all bands observed have complex shapes composed of the two, three or four components, due to the crystal field effect. The structure of the crystal seems to be monoclinic with $Z=4$.

Let us analyze now the results of in vilro cytotoxicity tests (Table II). Rather unexpected strong waste of tumor cells was observed. In fact, blocking of $-\mathrm{C}(\mathrm{O})-\mathrm{N}-\mathrm{P}(\mathrm{O})-\mathrm{N}$ part of ligand molecule changes almost nothing in biological activity of the system under consideration; its cytotoxicity is a little lower for lanthanide complexes, which seems to be confirmed by our preliminary in vivo cytotoxicity experiments [4]. Explanation of this phenomenon is not easy. Either the 
ending part of molecule plays an important role in its biological properties (which is the most probable) or the exchange of $\mathrm{Ca}^{2+}$ by $\mathrm{La}^{3+}$ is so fast that the free ligand reacts like its complexes with a lanthanide. The mechanism of biological activity of the systems tested will be the subject of further studies.

\section{TABLE II}

The results of cytotoxical experiments of samples. The numbers are $\%$ of dead cells after incubation with the compound.

\begin{tabular}{|c|c|c|c|}
\hline & $\mathrm{NaEu}(\Lambda z)_{4}$ & IIAz & $\mathrm{NaAz}$ \\
\hline $10 T_{1 / 2}$ & 96.0 & 100 & 99.7 \\
\hline \multirow[t]{2}{*}{$\mathrm{L}_{1}$} & 99.5 & 99.2 & 98.2 \\
\hline & 99.3 & 100 & 100 \\
\hline \multirow[t]{2}{*}{$\mathrm{MCF}$} & 91.7 & 100 & 100 \\
\hline & 97.0 & 100 & 100 \\
\hline \multirow[t]{2}{*}{ DETA } & 98.1 & 100 & 100 \\
\hline & 95.2 & 99.5 & 100 \\
\hline \multirow[t]{2}{*}{ Mew-132 } & 89.9 & 100 & 100 \\
\hline & 84.2 & 100 & 100 \\
\hline
\end{tabular}

Cell lines:

$10^{\top} T_{1 / 2}$ - line of normal cells (no-tumor),

$\mathrm{L}_{1}$ - Sarcoma $\mathrm{L}_{1}$,

MCF Mammary Carcinoma Female,

DETA - IIuman Colon Carcinoma,

Mew-132 - Melanoma IIuman.

\section{Conclusions}

Comparison of relative intensities of the $f-f$ transitions in the range of the hypersensitive one and of the IR spectral region, as well as the composition of the Stark level seem to indicate the similar structure of the system under study to that reported earlier for the compound $A$.

Substitution of the $\mathrm{NP}(\mathrm{O})\left(\mathrm{OCI}_{3}\right)_{2}$ ligand group by $\mathrm{NP}(\mathrm{O}) \mathrm{N}\left(\mathrm{CH}_{2}\right)_{2}$ changes biological function of the compound. Such an exchange plays only a minor role in binding of lanthanide ions.

In vitro cytotoxicity experiments on lanthanide complexes exhibit anticancer properties of the cell strains tested.

\section{Acknowledgments}

This work was sponsored by the Committee for Scientific Research. 


\section{References}

[1] O.N. Riebrova, W.N. Biyuslkin, T.I. Malinovskii, L.D. Protsenko, T.N. Dnieprova, Dokl. Akad. Nauk USSR 266, 1391 (1982).

[2] O.N. Riebrova, W.N. Biyushkin, L.D. Protsenko, T.N. Duieprova, T.I. Malinovskii, Dokl. Akad. Nauk USSR 274, 328 (1984).

[3] V. Amirkhanov, C. Janiczak, L. Macalik, J. Hanuza, J. Legendziewicz, J. Appl. Spectrosc. 62, 5 (1995).

[4] J. Legendziewicz, A. Graczyk, V. Amirklanov, P. Ziỏlkowski, paper in preparation. 